\title{
The tumor suppressor role of microRNA-338-3p in renal cell carcinoma
}

\author{
YIDONG HUANG, YANG WU, LI ZENG, WEI SHAN and LUGANG HUANG \\ Department of Pediatric Surgery, West China Hospital of Sichuan University, \\ Chengdu, Sichuan 610041, P.R. China
}

Received October 3, 2017; Accepted May 3, 2018

DOI: $10.3892 / \mathrm{ol} .2018 .8914$

\begin{abstract}
Human renal cell carcinoma (RCC) is the most common type of kidney malignancy in adults accounting for $2-3 \%$ of all adult malignancies. In China, RCC accounts for $\sim 0.5 \%$ of all cancer-associated mortalities, ranking 16th among all cancer types. For early-stage RCC, surgery is the recommended treatment. Molecularly targeted therapy is the preferred first-line treatment for clear-cell RCC. However, more potential targets are required. MicroRNA-338-3p (miR-338-3p) functions as a tumor suppressor in various cancers, but has not been studied in RCC. Accordingly, the present study investigated the role of miR-338-3p of RCC. It was demonstrated that miR-338-3p was present at low levels in RCC tissues. Also, overexpression of miR-338-3p inhibited cell proliferation and promoted cell apoptosis, and downregulation of miR-338-3p promoted cell proliferation. The 3' untranslated region of AKT serine/threonine kinase 3 was targeted by miR-338-3p. In conclusion, the data of the present study revealed the inhibitory function of miR-338-3p in RCC and suggested that miR-338-3p is novel therapeutic target for RCC, but further investigation is needed.
\end{abstract}

\section{Introduction}

Renal cell carcinoma (RCC), also called kidney cancer, is a heterogeneous disease. RCC begins in the lining of the proximal convoluted tubule, a component of the very small tubes in the kidney which transport primary urine. RCC is the most common kidneys malignancy in adults (1-4). The incidence of RCC is rapidly growing, increasing on average $1.1 \%$ over the last ten years (5). A total of 66,466 new cases of kidney tumors were diagnosed in China in 2012. If diagnosed early, RCC can be cured by surgical treatment. However, RCC is resistant to chemotherapy and radiotherapy. Since 2015,

Correspondence to: Dr Lugang Huang, Department of Pediatric Surgery, West China Hospital of Sichuan University, 37 Guo Xue Xiang, Chengdu, Sichuan 610041, P.R. China

E-mail: yidonghuang2001@163.com

Key words: human renal cell carcinoma, microRNA-338-3p, AKT3, cell growth molecularly targeted therapy is the preferred first-line treatment for clear-cell RCC (6).

MicroRNA (miRNA), is a small endogenous non-coding RNA, which negatively regulates gene expression by inhibiting translation of messenger RNA (mRNA) or targeting mRNAs for degradation (7). Aberrant miRNA expressions are involved in tumorigenesis of various cancers (8-13).

MicroRNA-338-3p (miR-338-3p) functions as a tumor suppressor in various cancers, including thyroid cancer (14), non-small-cell lung cancer $(15,16)$, hepatocellular carcinoma (17), breast cancer (18), and colorectal carcinoma (19).

However, the role of miR-338-3p in RCC remains unknown. In the present study, we investigated the function of miR-338-3p in RCC, and found that miR-338-3p is an inhibitor of tumor growth. We anticipate that our data may provide a potential molecular target for the treatment of RCC, but further investigation is needed.

\section{Materials and methods}

Tissue samples. Twelve RCC tissues samples were collected from the Department of Urology, West China Hospital of Sichuan University (Chengdu, China). The use of human tissues in the present study was evaluated and approved by the Ethics Committee of Sichuan University. Written informed consent were obtained from all patients enrolled in the presnet study and all specimens were handled and made anonymous as required according to the legal standards of China. All RCC tissues samples were evaluated and confirmed by a senior pathologist at the Sichuan University Cancer Center.

$H \& E$ staining. The twelve RCC tissues were processed in standard protocol for H\&E staining. Briefly, $4-\mu \mathrm{m}$-thick sections were cut. After deparaffinization and hydration, the slides were stained in hematoxylin for 3-5 min and washed in running water for $5 \mathrm{~min}$. After being differentiated in $1 \%$ acid alcohol, the slides were stained in $1 \%$ Eosin Y for $10 \mathrm{~min}$. Then these slides were dehydrated in increasing concentrations of alcohol and cleared in xylene prior to observation.

Cell culture. The RCC cell lines Caki-1 and 786-O cells, and human proximal convoluted tubule epithelial cell line HK-2, were purchased from the Cell bank of Sichuan University. All cells were maintained cultured in DMEM medium 
supplemented with $10 \%$ fetal bovine serum (Gibco BRL, Grand Island, NY, USA) in 6-well plate (Shengong, Shanghai, China).

Detection of miR-338-3p in samples and RCC cells. The expression of miR-338-3p in tissues samples and cells were analyzed by RT-qPCR. Briefly, the total RNA from tissue samples or cells were extracted using the TRIzol reagent according to the manufacturers's protocol (Invitrogen, Carlsbad, CA, USA). The level of miR-338-3p was determined by the TaqMan miRNA Assay (Thermo-Fisher, Waltham, MA, USA). The U6 snRNA was used as an internal loading control. RT-qPCR was performed on an ABI 7900HT instrument (Applied Biosystems, Foster City, CA, USA). The primers were synthesized and tested by the ShengRui Company (ShengRui, Chengdu, China) (20-23).

Overexpression and downregulation of miR-338-3p in RCC cells. The miR-338-3p levels in Caki-1 and 786-O cells was increased and decreased by miR-338-3p mimics and miR-338-3p antisense oligonucleotides (ASO), respectively. The miR-338-3p mimics and miR-338-3p ASO were both purchased from JingHong Biotechnoloy (Chengdu, China). Before transfection, the cells were cultured overnight ( $1 \times 10^{6}$ per well). The cells transfection was performed with Lipofectamine 2000 (Invitrogen), as recommended by the manufacturer's instructions.

Cell proliferation assay. The cellular growth was analyzed by the MTT assay. Briefly, cells were placed into 96-well plates at a density of $5 \times 10^{5} /$ well for overnight. Then remove the medium and replace it with $100 \mu 1$ of fresh culture medium, and the MTT reagent was added into the medium at a final concentration of $0.1 \mathrm{mg} / \mathrm{ml}$. Then the plates were incubated for $4 \mathrm{~h}$ at $37^{\circ} \mathrm{C}$. Next medium from each well was carefully removed and $100 \mu \mathrm{l}$ DMSO were added and incubated at $37^{\circ} \mathrm{C}$ for $15 \mathrm{~min}$. OD was measured on a microplate reader with a $570 \mathrm{~nm}$ filter (24).

Cell apoptosis analysis. Cells $\left(5 \times 10^{5}\right.$ cells $\left./ \mathrm{ml}\right)$ were suspended in the Annexin V-FITC (Abcam, Cambridge, UK) binding buffer. Then, Annexin V-FITC was added and the suspension was incubated for $15 \mathrm{~min}$ at room temperature. Afterwards, propidium iodide (PI; Abcam) was added to each sample. Next the samples were analyzed on a FACS analyzer instrument using the $488 \mathrm{~nm}$ excitation line (Argon-ion laser or solid state laser) and emission was detected at $530 \mathrm{~nm}$ (green, FITC) and 575-610 nm (orange, PI).

Prediction of the putative targets of $m i R-338-3 p$. The Targetscan software (http://www.targetscan.org/) was used to predict the putative targets of miR-338-3p.

Dual luciferase reporter assays. Cells were seeded at $1 \times 10^{5}$ per well and were serum-starved for $6 \mathrm{~h}$ pre-transfection. The 3'untranslated region (3'UTR) of Akt3 and mutated controls were cloned and inserted into the reporter plasmid (500 ng) and the pGL3-control (100 ng; Promega, Madison, WI, USA). MiR-338-3p p mimics were then transfected into the Caki-1 cells containing the wild-type or mutant 3'UTR plasmids with Lipofectamine 2000 (Invitrogen). Cells were harvested and luciferase activitity was measured after $24 \mathrm{~h}$ using the Dual-Luciferase Reporter Assay System (Huijun Company, Guangzhou, China). Mutant of Akt3 3'UTR were generated using the Site-Directed Mutagenesis kit (Promega).

Western blot analysis. Cells were frozen and lysed in lysis buffer $(150 \mathrm{mM} \mathrm{NaCl}, 50 \mathrm{mM}$ Tris-HCI, $1 \%$ Triton X-100 and $0.1 \%$ SDS) with the protease inhibitor cocktail (Sigma, St. Louis, MO, USA) and phosphatase inhibitor cocktail. For Akt3 western blotting, an anti-Akt3 antibody (Abcam) were used at a dilution of 1:1,000, followed by detection with a peroxidase-linked antibody to rabbit antibody $\operatorname{IgG}$ (1:2,000 dilution, Abcam). Proteins were detected with the ECL Western Blotting Detection Reagents (GE Healthcare, Chicago, IL, USA). Images were analyzed using Image $\mathbf{J}$ (NIH, Bethesda, MD, USA).

Statistical analysis. All experiments were repeated three times. Data are shown as mean \pm SD. Two-tailed Student's t-test was used to analyze the mean value between two groups; ANOVA was used to test the mean value among three or more than three groups. $\mathrm{P}<0.05$ was considered to indicate a statistically significant difference. All calculations were performed using SPSS software (version 16.0; SPSS Inc., Chicago, IL, USA).

\section{Results}

Low levels of miR-338-3p in RCC tissues samples. Initially, we collected 12 RCC tissues and the pathological images are shown in Fig. 1A. Next, the 12 RCC tissues samples and their matched tumor-adjacent samples were analyzed by RT-qPCR for miRNA-338-3p expression. We found that in every tissue tissues sample from each of the 12 RCC patients, the miRNA-338-3p level in the RCC sample was lower than the level in the matched tumor-adjacent tissue (Fig. 1B). In addition, we calculated the mean value of the 12 RCC tissues samples and matched tumor-adjacent tissues samples, and the results revealed that the mean value of miR-338-3p in RCC tissues was lower than the mean value detected in normal tissues (Fig. 1C).

Enforced expression of miR-338-3p inhibits cellular growth and promoted cell apoptosis. We assayed the miR-338-3p levels in RCC cell lines (Caki-1 and 786-O) by RT-qPCR analysis. The human proximal convoluted tubule epithelial cells, HK-2 were used as blank control. We found that the miR-338-3p levels in Caki-1 and 786-O cells was lower than in HK-2 cells (Fig. 2A). In addition, we transfected miR-338-3p mimics into Caki-1 and 786-O cells and found that miR-338-3p mimics very effectively increased the miR-338-3p levels in Caki-1 and 786-O (Fig. 2B). Since miR-338-3p mimics could increase the miR-338-3p levels in vitro, we analyzed cellular proliferation following miR-338-3p mimics transfection, and found that the increase miR-338-3p promoted the cells proliferation in Caki-1 and 786-O cells (Fig. 2C). Additionally, we evaluated the effect of miR-338-3p mimics on cells apoptosis, and found that transfection of miR-338-3p mimics increased 
A 1

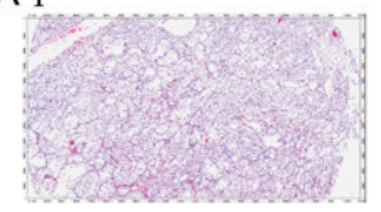

4

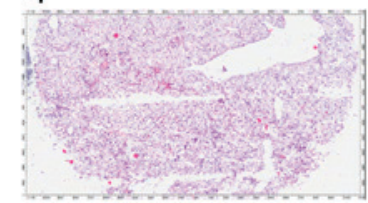

7

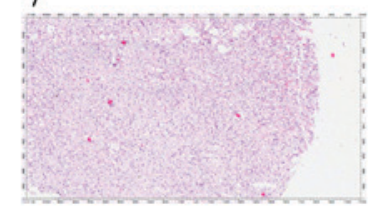

10

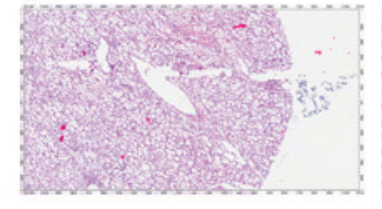

2

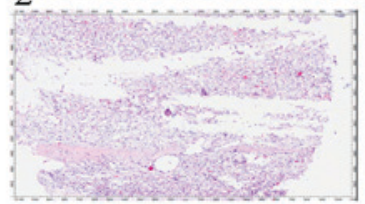

5

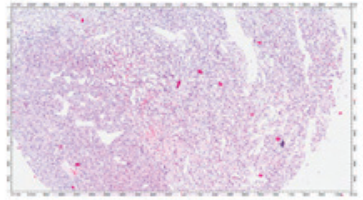

8

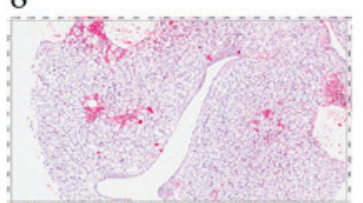

11

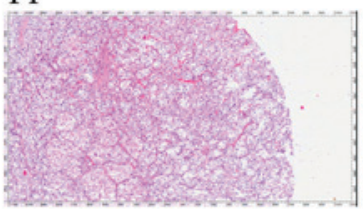

3

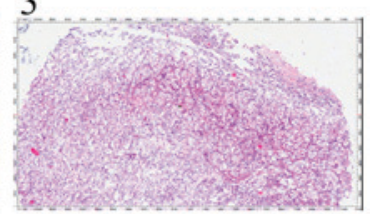

6

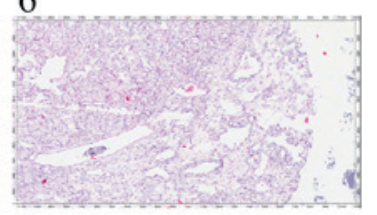

9

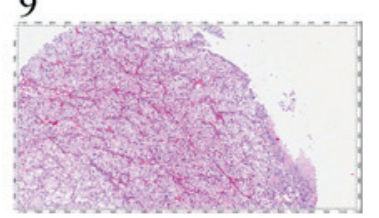

12

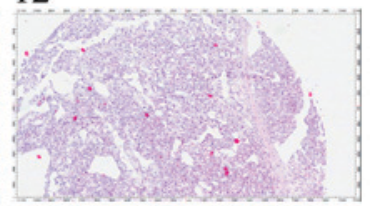

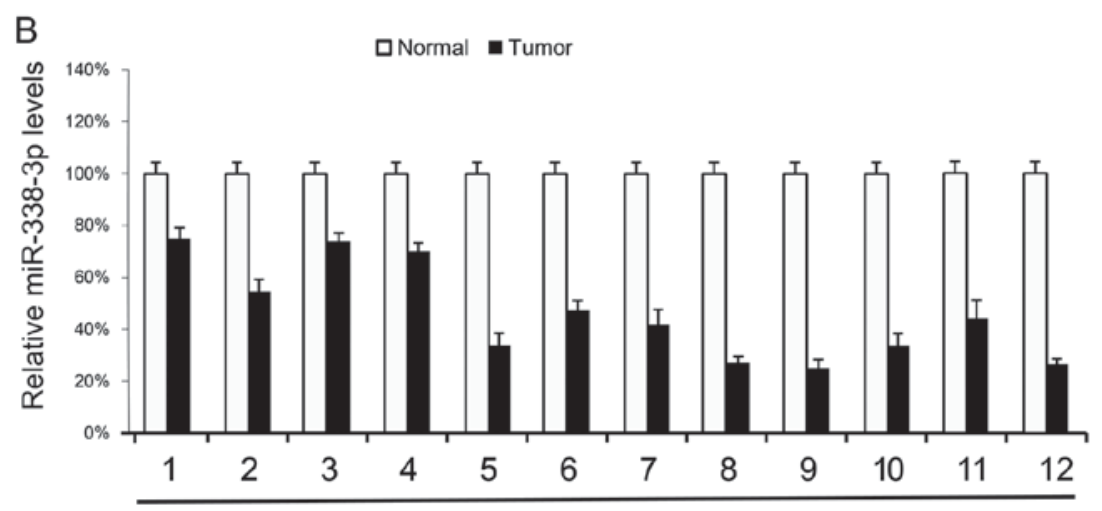

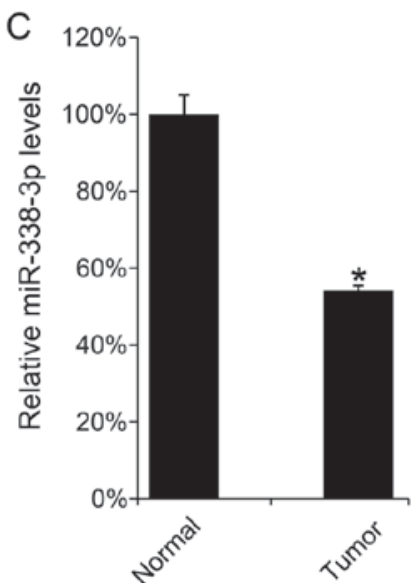

Figure 1. RCC tissue samples showed low levels of miR-338-3p. A total of 12 RCC tissues were collected from the West China Hospital of Sichuan University. The H\&E staining images are shown (A). The miR-338-3p levels in the 12 RCC tissues samples were analyzed by RT-qPCR (B). The mean values of miR-338-3p expression in 12 RCC tissues and their matched adjacent normal tissues were calculated $(\mathrm{C})$. The data are represented as the mean \pm SD. Each experiment was repeated at least three times. ${ }^{*} \mathrm{P}<0.05$. miR, microRNA; RCC, renal cell carcinoma.

the apoptosis rate (Fig. 2D). The Caki-1 cell morphological changes following $24 \mathrm{~h}$ miR-338-3p mimics and miR-338-3p ASO transfection were shown in Fig. 2E.

Downregulation of $m i R-338-3 p$ promotes cell growth. We also transfected miR-338-3p ASO into Caki-1 and 786-O cells to decrease the miR-338-3p levels. The miR-338-3p levels in cells were measured $24 \mathrm{~h}$ after miR-338-3p ASO transfection. We found that miR-338-3p was inhibited by miR-338-3p ASO (Fig. 3A). Moreover, cellular proliferation was assessed by MTT analysis, and the results revealed that miR-338-3p transfection promoted cellular proliferation (Fig. 3B).

AKT33 is a direct target of miR-338-3p. To understand of the mechanisms whereby which miR-338-3p suppressed RCC cells growth, we search the potential targets of miR-338-3p by bioinformatics approach. We found that the 3'-UTR of AKT3 could bind to the seed region of miR-338-3p (Fig. 4A). To confirm whether miR-338-3p could target $A K T 3$, we generated the mutant of 3 'UTR of AKT3 and cloned the mutant and wild-type version into luciferase reporter plasmids. MiR-338-3p mimics and mutant version were co-transfected into Caki-1 cells. We found, $24 \mathrm{~h}$ post transfection, that miR-338-3p mimics reduced the luciferase activity of the 3'UTR of AKT3 (wild-type version), but not that of mutated version of 3'UTR of $A K T 3$ (Fig. 4B). We also transfected miR-338-3p mimics into the Caki-1 cells, $48 \mathrm{~h}$ later, the $A K T 3$ protein levels were determined by western blot analysis, we found that miR-338-3p mimics could inhibit Caki-1 the expression of AKT3 in Caki-1 cells (Fig. 4C). 
A

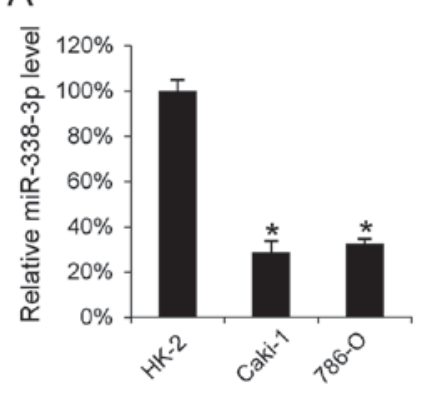

C

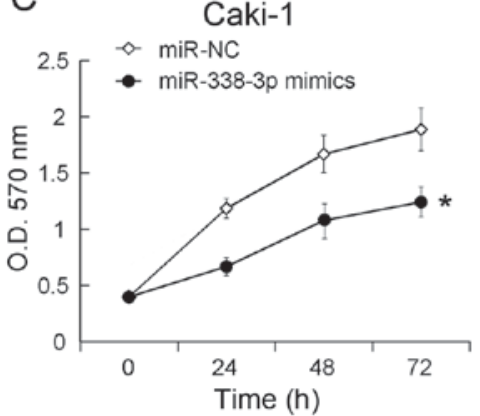

B
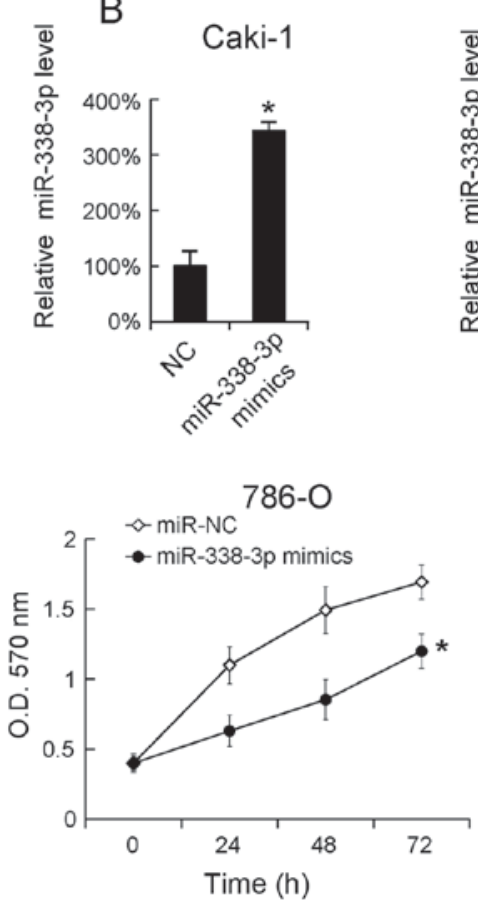

786-O
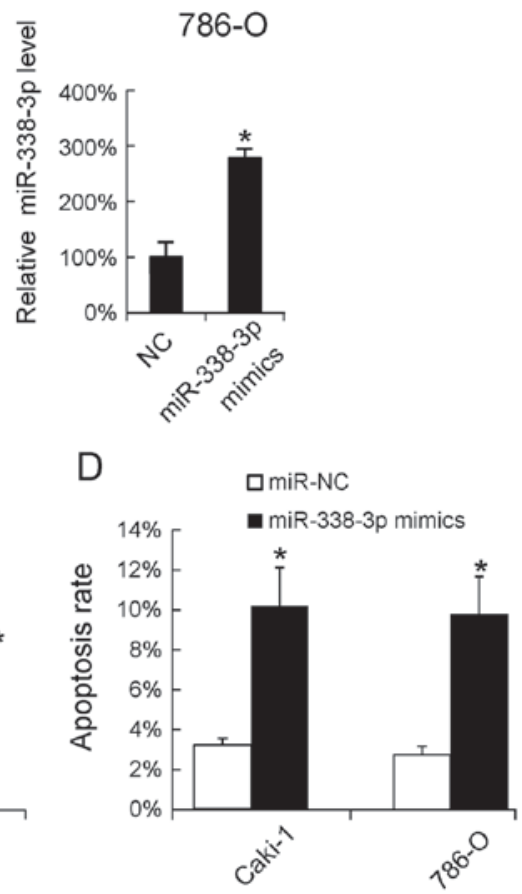

E

Caki-1

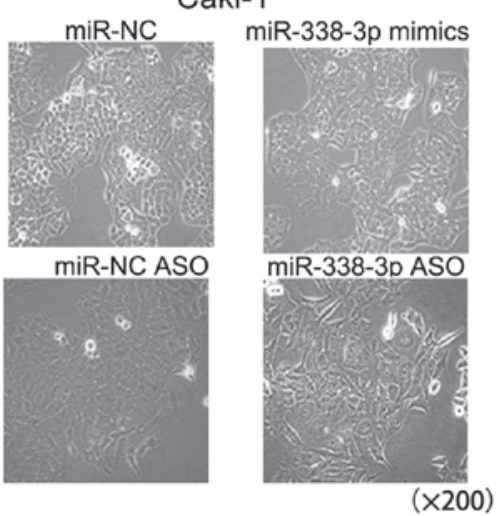

Figure 2. Overexpression of miR-338-3p inhibited Caki-1 and 786-O proliferation and promoted cells apoptosis. The miR-338-3p levels in normal renal tissues, Caki-1 and 786-O cells were analyzed by RT-qPCR. The miR-338-3p levels in HK-2 cells were arbitrarily defined as 100\% (A). Caki-1 and 786-O cells were seeded separately and then each was transfected with miR-338-3p mimics and NC mimics separately and $24 \mathrm{~h}$ later, the miR-338-3p expressions was evaluated by RT-qPCR (B). Following miR-338-3p mimics transfection, the cellular proliferation was assessed by the MTT assay (C). After $48 \mathrm{~h} \mathrm{miR-338-3p} \mathrm{mimics}$ transfection, Caki-1 and 786-O cells were stained with Annexin V-FITC and PI, and then the cell apoptosis rate was evaluated by FACS analysis (D). Caki-1 cell morphological changes following $24 \mathrm{~h} \mathrm{miR-338-3p} \mathrm{mimics} \mathrm{and} \mathrm{miR-338-3p} \mathrm{ASO} \mathrm{transfection} \mathrm{(magnification,} \mathrm{x} 200$ ) (E).The data are represented as the mean \pm S.D. Each experiment was repeated at least three times. ${ }^{*} \mathrm{P}<0.05$. miR, microRNA; NC, negative control; ASO, antisense oligonucleotides.

\section{Discussion}

In the present study, we examined the role of miR-338-3p in RCC and found that miR-338-3p exhibited a tumor suppressor activity in RCC. Additionally, we determined that the direct target gene of miR-338-3p is AKT3.

Previous studies have shown that miR-338-3p functions as a tumor suppressor in various cancers, including thyroid cancer (14), non-small-cell lung cancer $(15,16)$, hepatocellular carcinoma (17), breast cancer (18), colorectal carcinoma (19). Our study elucidated the role of miR-338-3p in RCC. In addition, we found that miR-338-3p inhibited RCC cells growth by targeting AKT3.

AKT3 is a member of Akt kinase family, also called $\mathrm{PKB}$, serine/threonine protein kinase family. Akt kinases are regulators of cell signaling in response to insulin and growth factors. Akt kinases play a role in cell proliferation, differentiation, apoptosis, and tumorgenesis (25-33). AKT is an oncogene which is involved in the development and progression of many cancers. Our data revealed that miR-338-3p could target AKT3 in vitro. Previous studies showed that AKT3 may act in two ways in the pathogenesis of cancer. One is that AKT3 is significantly correlated with a 76-gene signature DNA revealed by correlation analysis, and genomically amplified AKT3 activates the DNA repair pathway and promotes glioma progression (34); The other is AKT3 knockdown induces mitochondrial dysfunction in human cancer cells (35). However, the correlation between miR-338-3p and AKT3 expression in RCC samples was not investigated due to the limitation of RCC samples, and we 


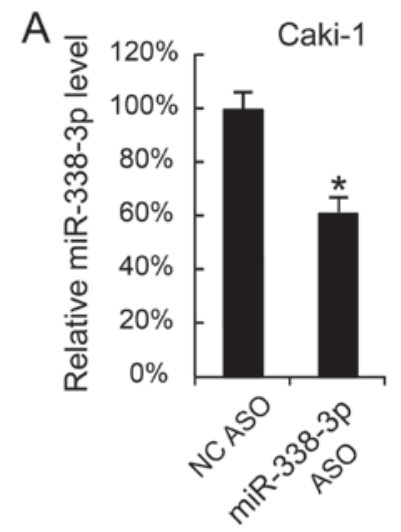

B

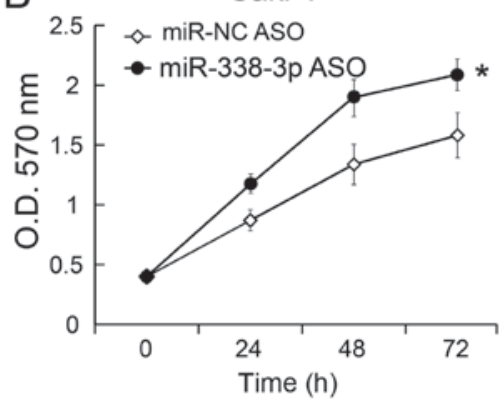

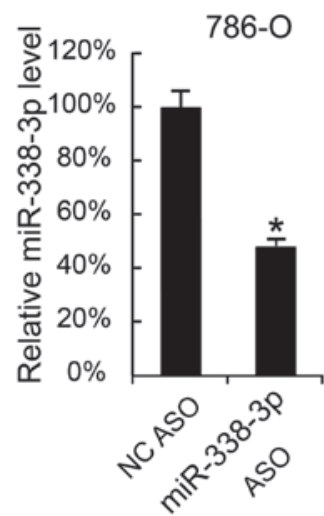

$786-0$

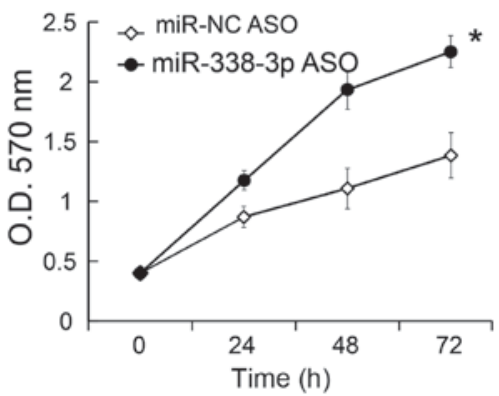

Figure 3. Suppression of miR-338-3p levels promoted Caki-1 and 786-O proliferation. Caki-1 and 786-O cells were seeded separately and then each was transfected with miR-338-3p ASO and 24 h later, the miR-338-3p expression was tested by RT-qPCR (A). After miR-338-3p ASO transfection, the cellular proliferation was analyzed (B). The data are represented as the mean \pm S.D. Each experiment was repeated at least three times. ${ }^{*}<0.05$. miR, microRNA; NC, negative control; ASO, antisense oligonucleotides.

\section{A Position 5483-5489 of Akt3 3' UTR}

hsa-miR-338-3p

Position 5483-5489 of Akt3 3' UTR

hsa-miR-338-3p

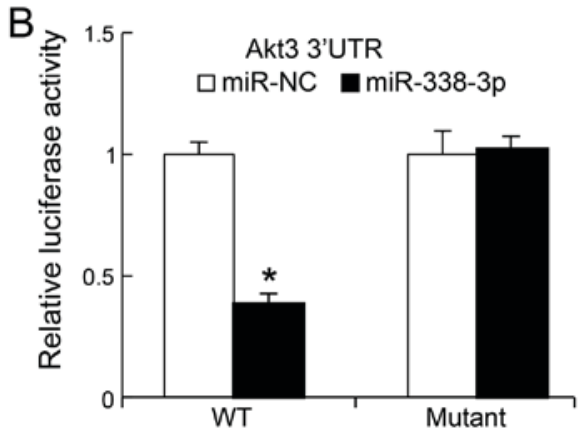

5' ....AAucagauUguggcaugcuggg..

| | | | | | |

3' GUUGUUUUAGUGACUACGACCU

5' ...CAAUCAGAUUGUGGCACCCACGG...

$1 * * * * * \mid$

3' GUUGUUUUAGUGACUACGACCU

C

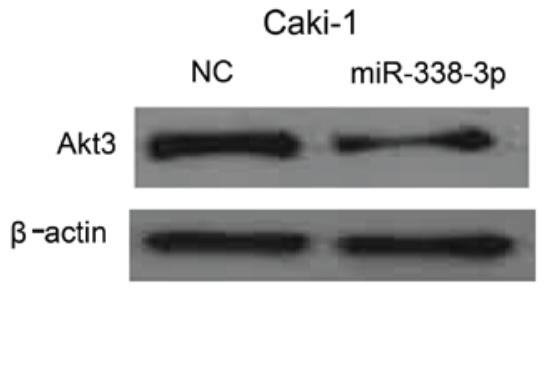

Figure 4. AKT3 was targeted by miR-338-3p in Caki-1 cells. The binding sites and its mutated version in AKT3 and miR-338-3p are shown (A). MiR-338-3p mimics and plasmid containing wild-type or mutated 3'UTR sequence of AKT3 were transfected into Caki-1 cells and 48 h later, the luciferase activity was analyzed (B). miR-338-3p mimics was transfected into Caki-1 cells, and the abundance of AKT3 protein was determined by western blotting (C). Each experiment was repeated at least three times. "P<0.05. UTR, untranslated region; Wt, wild-type; miR, microRNA; NC, negative control; ASO, antisense oligonucleotides.

will investigate this and the precise role of AKT3 in RCC in next study.

In conclusion, our data revealed the suppressive role in miR-338-3p in RCC. We hope our findings may provide a new therapeutic target for further investigation.

\section{Acknowledgements}

The present study was supported by a grant from Department of Sichuan Science and Technology (grant no. 2017FZ0057). 


\section{References}

1. Perlman E, Grosfeld J, Togashi K and Boccon-Gibod L: Pathology and genetics of tumors of the urinary system and male genital organs. World Health Organization Classification of Tumours. 1st edition. IARC Press, Lyon, France, pp48-52, 2004.

2. Rini BI, Campbell SC and Escudier B: Renal cell carcinoma. Lancet 373: 1119-1132, 2009.

3. Cohen HT and McGovern FJ: Renal-cell carcinoma. N Engl J Med 353: 2477-2490, 2005.

4. Gelb AB: Renal cell carcinoma: Current prognostic factors. Union Internationale Contre le Cancer (UICC) and the American Joint Committee on Cancer (AJCC). Cancer 80: 981-986, 1997.

5. Siegel RL, Miller KD and Jemal A: Cancer statistics, 2016. CA Cancer J Clin 66: 7-30, 2016.

6. Guo J, Ma J, Sun Y, Qin S, Ye D, Zhou F, He Z, Sheng X, Bi F, Cao D, et al: Chinese guidelines on the management of renal cell carcinoma (2015 edition). Ann Transl Med 3: 279, 2015.

7. Bartel DP: MicroRNAs: Target recognition and regulatory functions. Cell 136: 215-233, 2009.

8. Calin GA and Croce CM: MicroRNA signatures in human cancers. Nat Rev Cancer 6: 857-866, 2006.

9. Calin GA and Croce CM: MicroRNA-cancer connection: The beginning of a new tale. Cancer Res 66: 7390-7394, 2006.

10. Xie B, Ding Q, Han H and Wu D: miRCancer: A microRNA-cancer association database constructed by text mining on literature. Bioinformatics 29: 638-644, 2013.

11. Farazi TA, Hoell JI, Morozov P and Tuschl T: MicroRNAs in human cancer. Adv Exp Med Biol 774: 1-20, 2013.

12. Nugent M: microRNA and bone cancer. Adv Exp Med Biol 889: 201-230, 2015.

13. Del Vescovo V and Denti MA: microRNA and lung cancer. Adv Exp Med Biol 889: 153-177, 2015.

14. Sui GQ, Fei D, Guo F, Zhen X, Luo Q, Yin S and Wang H: MicroRNA-338-3p inhibits thyroid cancer progression through targeting AKT3. Am J Cancer Res 7: 1177-1187, 2017.

15. Zhang G, Zheng H, Zhang G, Cheng R, Lu C, Guo Y and Zhao G: MicroRNA-338-3p suppresses cell proliferation and induces apoptosis of non-small-cell lung cancer by targeting sphingosine kinase 2. Cancer Cell Int 17: 46, 2017.

16. Zhang P, Shao G, Lin X, Liu Y and Yang Z: MiR-338-3p inhibits the growth and invasion of non-small cell lung cancer cells by targeting IRS2. Am J Cancer Res 7: 53-63, 2017.

17. Zhang T, Liu W, Zeng XC, Jiang N, Fu BS, Guo Y, Yi HM, Li H, Zhang Q, Chen WJ and Chen GH: Down-regulation of microRNA-338-3p promoted angiogenesis in hepatocellular carcinoma. Biomed Pharmacother 84: 583-591, 2016.

18. Jin $Y$, Zhao $M$, Xie Q, Zhang H, Wang Q and Ma Q: MicroRNA-338-3p functions as tumor suppressor in breast cancer by targeting SOX4. Int J Oncol 47: 1594-1602, 2015.

19. Xue Q, Sun K, Deng HJ, Lei ST, Dong JQ and Li GX: MicroRNA-338-3p inhibits colorectal carcinoma cell invasion and migration by targeting smoothened. Jpn J Clin Oncol 44: 13-21, 2014.

20. Li D, Liu X, Lin L, Hou J, Li N, Wang C, Wang P, Zhang Q, Zhang P, Zhou W, et al: MicroRNA-99a inhibits hepatocellular carcinoma growth and correlates with prognosis of patients with hepatocellular carcinoma. J Biol Chem 286 36677-36685, 2011.
21. Song B, Zhang C, Li G, Jin G and Liu C: MiR-940 inhibited pancreatic ductal adenocarcinoma growth by targeting MyD88. Cell Physiol Biochem 35: 1167-1177, 2015.

22. Zhou Q and Yu Y: Upregulated CDK16 expression in serous epithelial ovarian cancer cells. Med Sci Monit 21: 3409-3414, 2015.

23. Li H, Xu Y, Qiu W, Zhao D and Zhang Y: Tissue miR-193b as a novel biomarker for patients with ovarian cancer. Med Sci Monit 21: 3929-3934, 2015.

24. Mosmann T: Rapid colorimetric assay for cellular growth and survival: Application to proliferation and cytotoxicity assays. J Immunol Methods 65: 55-63, 1983.

25. Gai D, Haan E, Scholar M, Nicholl J and Yu S: Phenotypes of AKT3 deletion: A case report and literature review. Am J Med Genet A 167A: 174-179, 2015.

26. Vivanco I and Sawyers CL: The phosphatidylinositol 3-kinase-AKT pathway in human cancer. Nat Rev Cancer 2: 489-501, 2002

27. Cantley LC and Neel BG: New insights into tumor suppression: PTEN suppresses tumor formation by restraining the phosphoinositide 3-kinase/AKT pathway. Proc Natl Acad Sci USA 96: 4240-4245, 1999.

28. Dimmeler S, Aicher A, Vasa M, Mildner-Rihm C, Adler K, Tiemann M, Rütten H, Fichtlscherer S, Martin H and Zeiher AM: HMG-CoA reductase inhibitors (statins) increase endothelial progenitor cells via the PI 3-kinase/Akt pathway. J Clin Invest 108: 391-397, 2001.

29. Stitt TN, Drujan D, Clarke BA, Panaro F, Timofeyva Y, Kline WO, Gonzalez M, Yancopoulos GD and Glass DJ: The IGF-1/PI3K/Akt pathway prevents expression of muscle atrophy-induced ubiquitin ligases by inhibiting FOXO transcription factors. Mol Cell 14: 395-403, 2004.

30. Fresno Vara JA, Casado E, de Castro J, Cejas P, Belda-Iniesta C and González-Barón M: PI3K/Akt signalling pathway and cancer. Cancer Treat Rev 30: 193-204, 2004.

31. Osaki M, Oshimura M and Ito H: PI3K-Akt pathway: Its functions and alterations in human cancer. Apoptosis 9: 667-676, 2004.

32. Manning BD, Tee AR, Logsdon MN, Blenis J and Cantley LC: Identification of the tuberous sclerosis complex-2 tumor suppressor gene product tuberin as a target of the phosphoinositide 3-kinase/akt pathway. Mol Cell 10: 151-162, 2002.

33. Brunet A, Datta SR and Greenberg ME: Transcription-dependent and-independent control of neuronal survival by the PI3K-Akt signaling pathway. Curr Opin Neurobiol 11: 297-305, 2001.

34. Turner KM, Sun Y, Ji P, Granberg KJ, Bernard B, Hu L, Cogdell DE, Zhou X, Yli-Harja O, Nykter M, et al: Genomically amplified Akt3 activates DNA repair pathway and promotes glioma progression. Proc Natl Acad Sci USA 112: 3421-3426, 2015.

35. Kim M, Kim YY, Jee HJ, Bae SS, Jeong NY, Um JH and Yun J: Akt3 knockdown induces mitochondrial dysfunction in human cancer cells. Acta Biochim Biophys Sin (Shanghai) 48: 447-453, 2016. 